\title{
Isolated brachydactyly type E caused by a HOXD13 nonsense mutation: a case report
}

Aleksander Jamsheer ${ }^{1,2^{*}}$, Anna Sowińska ${ }^{1,2}$, Leszek Kaczmarek ${ }^{3}$ and Anna Latos-Bieleńska ${ }^{1,2}$

\begin{abstract}
Background: Brachydactyly type E (BDE; MIM\#113300) is characterized by shortening of the metacarpal, metatarsal, and often phalangeal bones, and predominantly affects postaxial ray(s) of the limb. BDE may occur as an isolated trait or as part of a syndrome. Isolated BDE is rare and in the majority of cases the molecular pathogenesis has so far not been resolved. Originally, the molecular cause of isolated BDE has been unravelled in 2 families and shown to result from heterozygous missense mutations in the homeodomain of the HOXD13 gene. Since the initial manuscript, one further HOXD13 mutation has been reported only in a single family manifesting isolated BDE.

Case Presentation: In this paper, we report on a Polish family exhibiting isolated BDE caused by a novel nonsense heterozygous HOXD13 mutation. We investigated a Polish female proband and her father, both affected by isolated BDE, in whom we identified a nonsense heterozygous mutation c.820C > T(p.R274X) in the HOXD13 gene. So far, only two missense HOXD13 substitutions (p.S308C and p.I314L), localized within the homeodomain of the HOXD13 transcription factor, as well as a single nonsense mutation (p.E181X) were associated with BDE. Both missense changes were supposed to alter DNA binding affinity of the protein.
\end{abstract}

Conclusion: The variant p.R274X identified in our proband is the fourth HOXD13 mutation, and the second truncating (nonsense) mutation, reported to result in typical isolated BDE. We refer our clinical and molecular findings to the previously described HOXD13 associated phenotypes and mutations.

Keywords: brachydactyly type E, BDE, isolated brachydactyly, nonsense mutation, HOXD13

\section{Background}

Brachydactyly type E (BDE; MIM\#113300) is characterized by shortening of the metacarpal, metatarsal, and often phalangeal bones, and predominantly affects postaxial ray(s) of the limb [1]. In most cases BDE is syndromic and occurs within the clinical spectrum of Turner syndrome, Albright hereditary osteodystrophy (AHO; MIM\#103580) or 2q37 deletion [1]. Isolated BDE is rare and in the majority of cases has unknown genetic background. Originally, the molecular cause of isolated BDE has been unravelled in 2 families and shown to result from heterozygous missense mutations in the homeodomain of the HOXD13 gene [2]. Some patients from these families presented not only with BDE, but also with overlapping features of brachydactyly type D

\footnotetext{
* Correspondence: jamsheer@wp.pl

'Department of Medical Genetics, University of Medical Sciences in Poznan, Poland, ul. Grunwaldzka 55 paw. 15, 60-352 Poznan, Poland

Full list of author information is available at the end of the article
}

(BDD), defined as shortening and broadening of the thumbs [2].

Missense variants affecting other residues of the Cterminal HOXD13 homeodomain may also give rise to different and more severe limb phenotypes such as synpolydactyly (SPD; MIM\#186000) or syndactyly type 5 (MIM\#186300), whereas expansion or contraction of the $\mathrm{N}$-terminal HOXD13 polyalanine tract usually results in SPD [3-6]. Most patients affected by SPD show fusion of third and fourth fingers and fourth and fifth toes, accompanied with incomplete or complete insertional polydactyly within the syndactylous web. Affected individuals may also have external rotation of fifth toes, clinodactyly, and camptodactyly (Figure 1H, I \&1J present a family with classical SPD caused by insertion of 7 alanines within the HOXD13 polyalanine tract). The clinical presentation of SPD is highly heterogeneous and varies within the affected individual (asymmetrical expressivity) or in the family. Severe manifestation and 

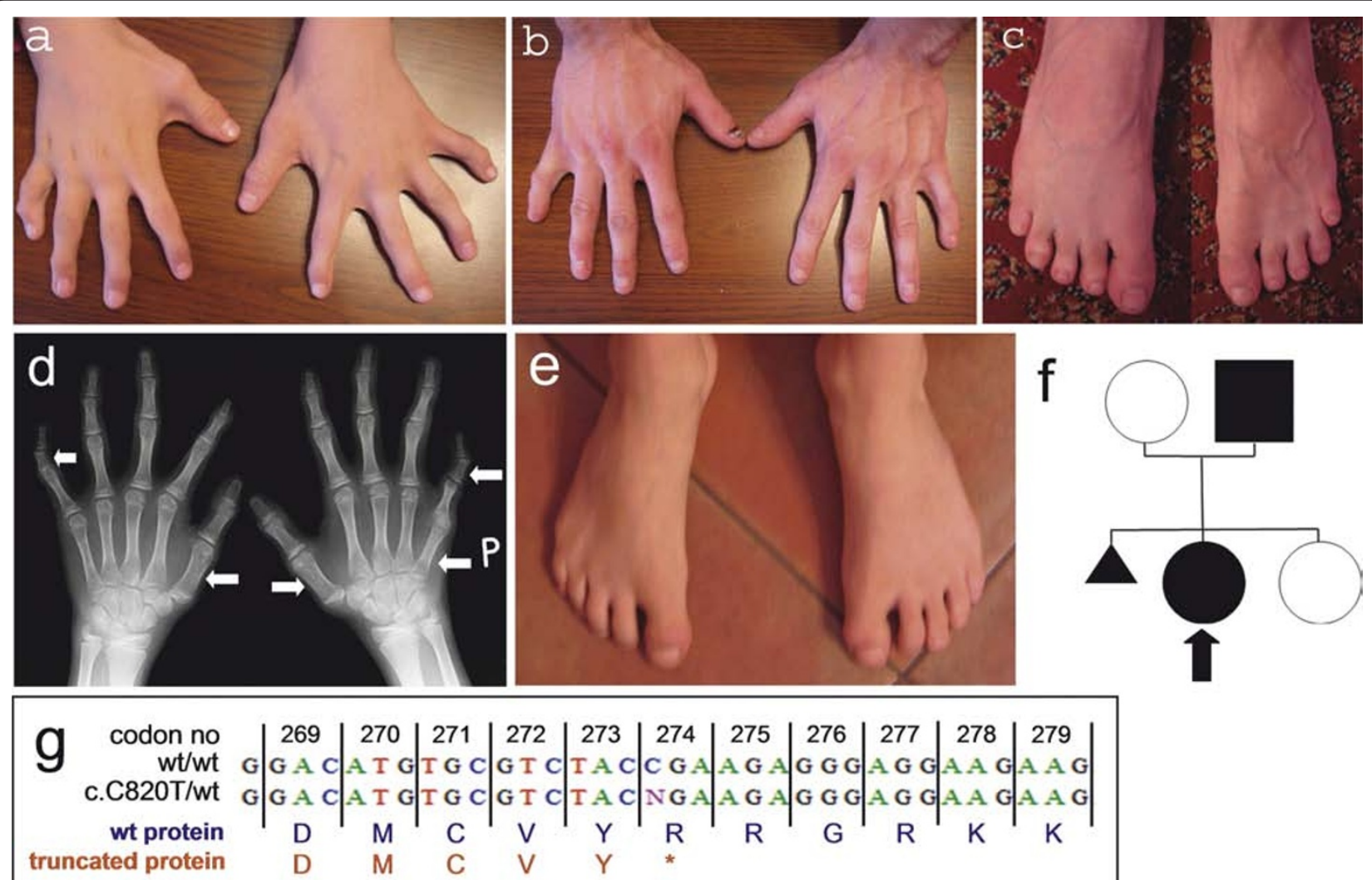

truncated protein
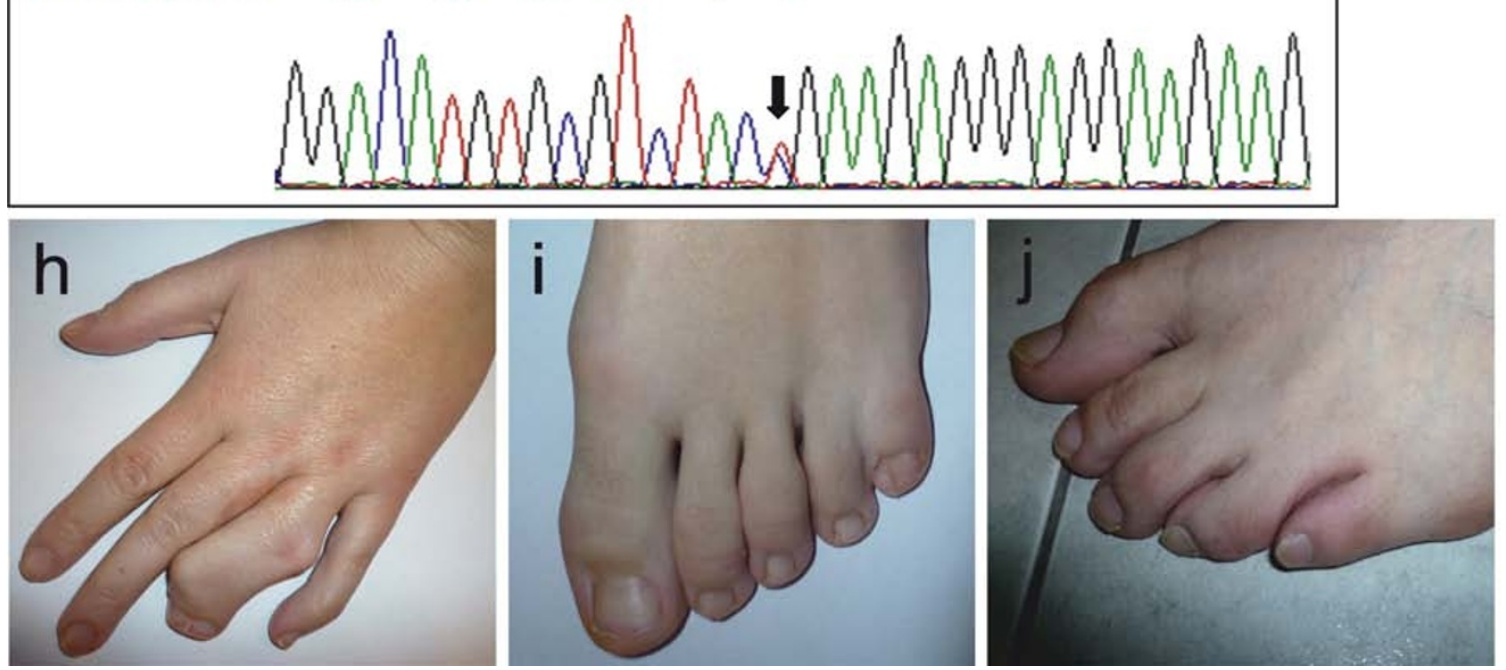

Figure 1 A-Brachydactyly type $\mathrm{E}(\mathrm{BDE})$ in the proband characterized by shortened $\mathrm{V}^{\text {th }}$ fingers, $\mathrm{B}, \mathrm{C}$-Clinical picture of BDE (shortened $\mathrm{V}^{\text {th }}$ fingers and toes) in the proband's father, D-X-ray of the proband's hands showing shortening of the $\mathrm{V}^{\text {th }}$ right metacarpal, bilateral shortening and broadening of the $I^{\text {st }}$ metacarpals, and bilateral shortening of the middle phalanges of $\mathrm{V}^{\text {th }}$ fingers (skeletal abnormalities are indicated by the white arrows), E-Feet of the proband showing broad halluces and no clinically evident BDE, FPedigree of the presented BDE family (proband is indicated by an arrow), G-Chromatogram picture showing the c.820C > T(p.R274X) HOXD13 mutation. Wild-type HOXD13 protein sequence is presented in blue, whereas truncated protein variant is shown in red. $\mathbf{H}-$ Hand malformation typical for synpolydactyly (SPD) spectrum (syndactyly of fingers $3 / 4$ with insertional polydactyly within the syndactylous web), I Typical SPD foot malformation characterized by syndactyly of $4 / 5$ toes, $\mathbf{J}$ - External rotation of $5^{\text {th }}$ toe often seen in SPD patients (SPD in patients shown in pictures $\mathrm{H}, \mathrm{I}, \mathrm{J}$ results from insertions of $7 \mathrm{Ala}$ in the polyalanine tract). 
incomplete penetrance may occur within the same pedigree $[4,5]$.

HOXD13 is a member of a large family of developmental homeobox transcription factor genes. Human, as well as other vertebrate genomes contain $39 H O X$ genes organized into four clusters (HOXA, HOXB, HOXC, and $H O X D) . H O X$ genes are involved in body plan formation and embryonic development of many internal organs, such as central nervous system, gastrointestinal and genitourinary tract. They also play a critical role in limb development by influencing limb patterning along proximodistal and anteroposterior axes. In general, the position of the gene in each cluster corresponds to its spatio-temporal expression during limb development in an order from 3' to 5' end. Thus, homologues located at the 3' end of the cluster are expressed earlier in development and in more proximal and anterior structures, whereas those located at the 5 ' end are expressed later and in more posterior and distal embryonic regions $[7,8]$. The HOXD13 gene consists of two exons and encodes a protein built of 335 amino acids. Exon 1 contains an $\mathrm{N}$-terminal tract comprised of 15 polyalanine residues in wild-type protein. Exon 2 carries a sequence for a highly conserved C-terminal DNA binding domain, known as homeodomain, through which HOXD13 interacts with consensus DNA sequence. A schematic view of the protein structure and a summary of annotated mutations are given in Figure 2.

Recently, Klopocki et al. [9] described causative alterations (microdeletion and point mutations) in the PTHLH gene in five unrelated families affected by BDE and short stature. Since the initial paper of Johnson et al. from 2003 [2], HOXD13 mutation has been reported only in a single family manifesting isolated BDE [10]. In addition, only 8 out of 24 annotated HOXD13 mutations resulted in a premature termination of the protein synthesis [10-17]; see Figure 2). Thus, genotype-phenotype correlation for truncating HOXD13 variants remains poorly known.

In this paper, we relate on a Polish family exhibiting isolated BDE caused by a nonsense heterozygous HOXD13 mutation and refer our clinical and molecular finding to previously described HOXD13 associated phenotypes and mutations.

\section{Case presentation}

We investigated a 10 year old female proband and her 28 year old father of Polish origin, both affected by isolated BDE (a family tree is shown in Figure 1F). Skeletal manifestations of the proband (Figure 1A, D \&1E) comprised shortening of the $\mathrm{V}^{\text {th }}$ right metacarpal without shortening of $\mathrm{IV}^{\mathrm{th}}$ metacarpal bones, bilateral shortening and broadening of the $\mathrm{I}^{\text {st }}$ metacarpals, bilateral shortened, trapezoid middle phalanges of $\mathrm{V}^{\text {th }}$ fingers resulting in rather severe clinodactyly, as well as contractures and deviations of the fingers II-IV. Upon clinical examination feet of the proband showed broad halluces and no clinically recognizable BDE phenotype. Unfortunately, since no X-ray was available, we were unable to rule out all possible skeletal foot abnormalities. The proband's father (Figure 1B \&1C) manifested finger contractures, shortening of the $\mathrm{V}^{\text {th }}$ fingers and toes most probably due to shortened $\mathrm{V}^{\text {th }}$ metacarpals and metatarsal, shortened finger nails of the $\mathrm{V}^{\text {th }}$ fingers most likely resulting from hypoplastic distal phalanges, as well as short thumbs. Unfortunately, the patient decided not to undergo $\mathrm{X}$-ray examination, thus we were unable to delineate skeletal findings in more detail. Both patients had normal stature and normal psychomotor development.

Genomic DNA was extracted from peripheral blood leukocytes according to salting-out method [18]. The entire coding sequence of the HOXD13 gene comprised of two exons and the flanking intronic regions (GenBank NM_000523.3) were amplified in PCR reactions and directly sequenced using dye-terminator chemistry (kit v.3, ABI 3130XL). Sequences of the primers used for amplification and sequencing PCR reactions are given in table 1. PCR conditions used for HOXD13 amplification where as follows: 40 cycles, denaturation in $95^{\circ} \mathrm{C}\left(30^{\prime}\right)$, annealing $\left(30^{\prime}\right)$ with temperature starting from $63^{\circ} \mathrm{C}$, decreasing to $55^{\circ} \mathrm{C}$ (touchdown PCR $-0.2^{\circ} \mathrm{C}$ per cycle), and elongation in $72^{\circ} \mathrm{C}\left(45^{\prime}\right)$. Multiplex ligation-dependent probe amplification (MLPA) for both exons of the HOXD13 was performed by means of P179 commercial kit according to the manufacturer's protocol (MRC Holland).

The proband and her father carried a nonsense heterozygous mutation c.820C > T(p.R274X) in the HOXD13 gene (Figure 1G). Presence of this mutation was excluded in 208 ethnically matched control chromosomes. MLPA ruled out intragenic copy number changes within the HOXD13 in both proband and her father (i.e. deletion/duplication).

\section{Discussion}

So far, only a few HOXD13 mutations are known to result in an isolated brachydactyly phenotype $[2,10]$. Originally, two missense mutations (p.S308C and p. I314L), localized within the homeodomain of the HOXD13 transcription factor were associated with overlapping features of BDE and BDD [2]. Both changes were supposed to alter DNA binding affinity of the protein [2]. Additionally, one nonsense variant p.E181X was described by Brison et al. [10] in a Belgian family presenting with isolated BDE, but neither detailed clinical description nor pictures were provided for this case. The variant p.R274X identified in our proband and her 


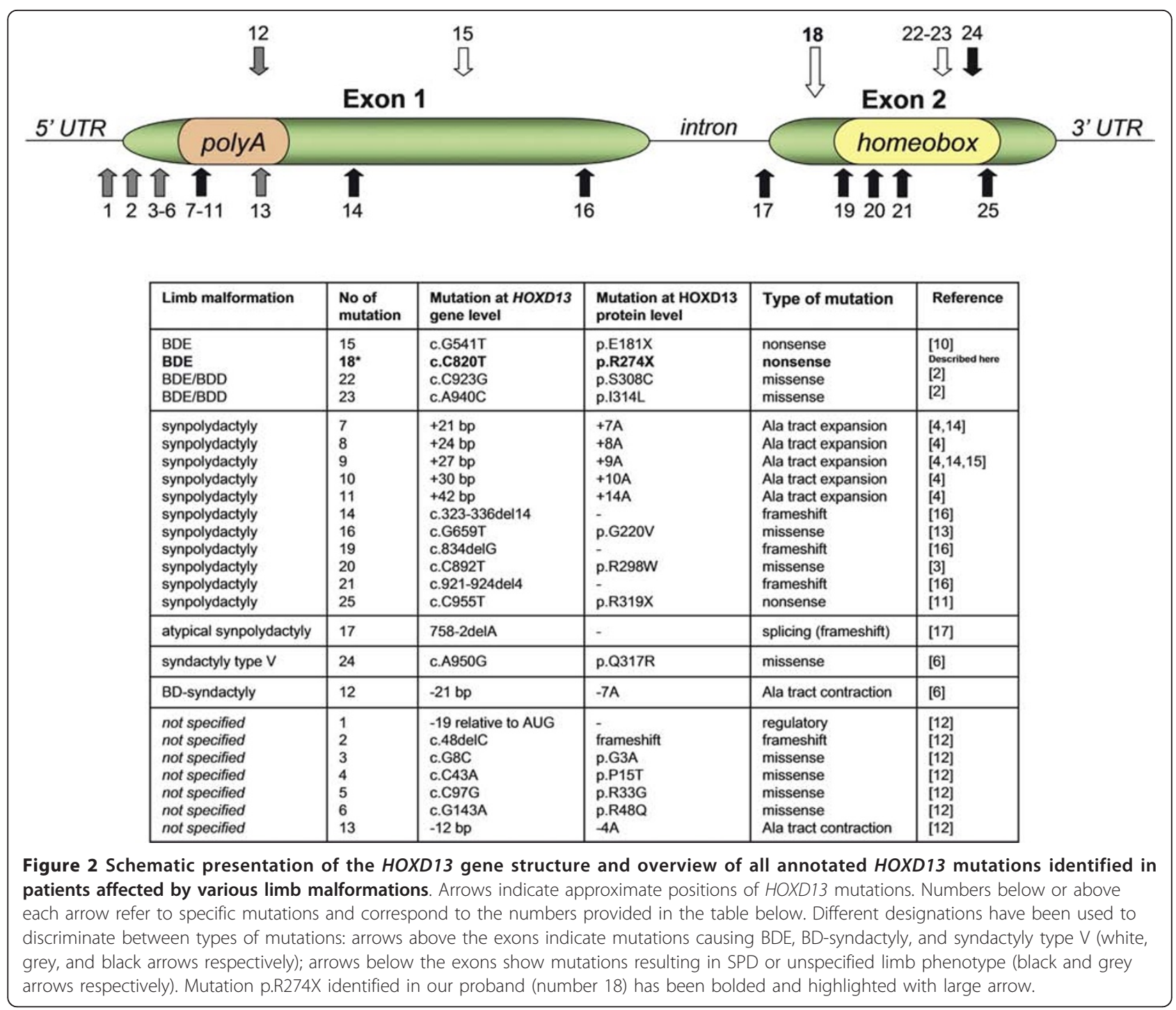

father is the fourth HOXD13 mutation, and the second truncating (nonsense) mutation reported to result in typical isolated BDE/BDD. Noteworthy, clinical manifestation of BDE in our patients shared significant similarities with the features reported by Johnson et al. [2] in the two original families. In addition to metacarpal brachydactyly (BDE), both ours and Johnson's patients had clinodactyly, deviations, and contractions of fingers, short thumbs with apparently hypoplastic distal phalanges, and hypoplastic middle and distal phalanges, especially of the little fingers. Unlike Johnson's families, none of our patients showed syndactyly of 3/4, ring finger duplication or long distal digit phalanges. Moreover, metacarpal brachydactyly in our case was confined solely to $\mathrm{V}^{\text {th }}$ digits, whereas in other BDE patients also affected other rays $[1,2]$.

The mutant HOXD13 protein (p.R274X) synthesized in our proband is predicted to lack the entire homeodomain and hence cannot bind to DNA consensus. Likewise, the same pathogenic mechanism most probably

Table 1 Sequences of the primers used for HOXD13 gene amplification and sequencing.

\begin{tabular}{llll}
\hline $\begin{array}{l}\text { Exon } \text { name } \\
\text { (fragment) }\end{array}$ & Forward primer sequence $\mathbf{5}^{\prime}$ - $\mathbf{3}^{\prime}$ & Reverse primer sequence $\mathbf{5}^{\prime}$ - 3' & $\begin{array}{c}\text { Product size } \\
\text { (bp) }\end{array}$ \\
\hline HOXD13_e1(a) & TATAAACGTCCCGCGATGAG & ATTCTGCTGTAAGCCCACGC & 644 \\
\hline HOXD13_e1(b) & CAAAGAGTGCCCAGCACC & TAACCCTGGTCACGTGTGG & 599 \\
\hline HOXD13_e2 & AAAATTTCCTGCACCCCTG & CACAAAATTTGCCACCATTG & 491 \\
\hline
\end{tabular}


exists in the case of p.E181X variant which also results in isolated BDE (see Figure 2). On the other hand, the most terminal of all known truncating HOXD13 mutation (p.R319X), which is localized at the very end of the homeodomain sequence, produces SPD. Out of truncating HOXD13 alterations, four frameshift and one splicing mutation have been additionally described in the literature. Four of them caused a phenotype referred to as "SPD with foot anomalies" (MIM\#186000), in which classic SPD was accompanied by supernumerary digit between $\mathrm{I}^{\text {st }}-\mathrm{II}^{\text {nd }}$ and often $\mathrm{IV}^{\text {th }}-\mathrm{V}^{\text {th }}$ metatarsals $[16,17]$. The most plausible mechanism through which all truncating mutations exert their pathogenic effect is functional haploinsufficiency of HOXD13. Conversely, missense substitutions affecting different residues of homeodomain alter rather than abolish DNA binding ability of the mutant protein. Hence, mixed both gainand loss-of-function mechanisms have been postulated to account for different limb phenotypes associated with these mutations [2,6]. Despite different mutational mechanisms of p.I314L and p.S308C substitutions in reference to our mutation (p.R274X), there has been a substantial overlap in the clinical phenotype. More severe presentation associated with missense mutations can be thus explained by their dominant-negative effect.

Another example of a homeotic gene known from its pleiotropic pathogenic effect is a HOXD13 paralogue belonging to a HOXA cluster-HOXA13. Mutations in this gene may give rise to different phenotypes, depending on their type and intragenic location. While nonsense truncating mutations $\mathrm{N}$-terminal to or within the homeodomain, as well as expansions of polyalanine tract cause Hand-foot-genital syndrome (HFGS also known as Hand-foot-uterus syndrome; HFUS; MIM\#140000), missense mutation within the homeodomain has been associated with Guttmacher syndrome (MIM \#176305), a phenotype in which HFGS features are accompanied with postaxial polydactyly of the hands and uniphalangeal second toes $[19,20]$.

In the developmental context, Hoxd13 has been shown to suppress chondrogenesis in the interdigital space, thus being responsible for proper digit formation. A loss-of-function mutation in mouse Hoxd13 results in down-regulation of Raldh 2 and thereby in low tissue concentration of retinoic acid. This induces expression of Sox9 in the interdigital mesenchyme, the formation of interdigital condensation, and consequently, polydactyly [21]. Conversely, missense mutations of human HOXD13 localized in the homeodomain exert their pathogenicity via gain-of-function effect that possibly reduces level of SOX9 expression. Of note, Sox 9 is also a target molecule of Pthlh (Pthrp) signaling in prehypertrophic chondrocytes in the growth plate. Pthlh increases transcriptional activity of $\operatorname{Sox} 9$, helps to maintain chondrocyte phenotype of the cells in the prehypertrophic zone, and inhibits their differentiation to hypertrophic chondrocytes [22]. Hence, haploinsufficiency of human PTHLH in BDE patients may at least partly result in reduced transcriptional activity of $S O X 9$, which fails to maintain the chondrocyte phenotype in prehypertrophic zone and, in turn, promotes their maturation to hypertrophic chondrocytes.

\section{Conclusions}

Isolated BDE can be caused by either HOXD13 nonsense mutations or missense substitutions within the homeodomain of the HOXD13 transcription factor. HOXD13 is a pleiotropic gene associated with various limb malformations. Most of the mutations occurring within the gene produce SPD, and not BDE.

\section{Consent}

Written informed consent was obtained from the patient for publication of this case report and any accompanying images. A copy of the written consent is available for review by the Editor-in-Chief of this journal.

\section{Acknowledgements and funding}

This work was supported by a grant from the Polish Ministry of Science and Higher Education (495/N-NIEMCY/2009/0).

\section{Author details}

${ }^{1}$ Department of Medical Genetics, University of Medical Sciences in Poznan, Poland, ul. Grunwaldzka 55 paw. 15, 60-352 Poznan, Poland. ${ }^{2} \mathrm{NZOZ}$ Center for Medical Genetics, Poznan, Poland, ul. Grudzieniec 4, 60-601 Poznan, Poland. ${ }^{3}$ Department of Traumatology, Orthopedics and Hand Surgery, University of Medical Sciences in Poznan, Poland, ul. 28 czerwca 1956 r. 135/ 147, 61-545 Poznan, Poland.

\section{Authors' contributions}

AJ-consulted the family, conceived the manuscript; AS-performed molecular testing of the patients and controls; LK-consulted the family of interest; ALBcritically revised the manuscript. All authors read and approved the final manuscript.

\section{Competing interests}

The authors declare that they have no competing interests.

Received: 19 May 2011 Accepted: 10 January 2012

Published: 10 January 2012

\section{References}

1. Schwabe GC, Mundlos S: Genetics of congenital hand anomalies. Handchir Mikrochir Plast Chir 2004, 36(2-3):85-97.

2. Johnson D, Kan S, Oldridge M, Trembath RC, Roche P, Esnouf RM, Giele H, Wilkie AOM: Missense mutations in the homeodomain of HOXD13 are associated with brachydactyly types D and E. Am J Hum Genet 2003, 72:984-997.

3. Debeer P, Bacchelli C, Scambler PJ, De Smet L, Fryns JP, Goodman FR: Severe digital abnormalities in a patient heterozygous for both a novel missense mutation in HOXD13 and a polyalanine tract expansion in HOXA13. J Med Genet 2002, 39:852-856.

4. Muragaki Y, Mundlos S, Upton J, Olsen BR: Altered growth and branching patterns in synpolydactyly caused by mutations in HOXD13. Science 1996, 272(5261):548-551.

5. Goodman FR, Mundlos S, Muragaki Y, Donnai D, Giovannucci-Uzielli ML, Lapi E, Majewski F, McGaughran J, McKeown C, Reardon W, Upton J, 
Winter RM, Olsen BR, Scambler PJ: Synpolydactyly phenotypes correlate with size of expansions in HOXD13 polyalanine tract. Proc Natl Acad SCl 1997, 94(14):7458-7463.

6. Zhao X, Sun M, Zhao J, Leyva JA, Zhu H, Yang W, Zeng X, Ao Y, Liu Q, Liu G, Lo WHY, Jabs EW, Amzel LM, Shan X, Zhang X: Mutations in HOXD13 underlie syndactyly type $V$ and a novel brachydactylysyndactyly syndrome. Am J Hum Genet 2007, 80(2):361-371.

7. Krumlauf R: Hox genes in vertebrate development. Cell 1994, 78:191-201.

8. Zakany J, Duboule D: The role of Hox genes during vertebrate limb development. Curr Opin Genet Dev 2007, 17(4):359-66.

9. Klopocki E, Hennig BP, Dathe K, Koll R, de Ravel T, Baten E, Blom E, Gillerot Y, Weigel JF, Kruger G, Hiort O, Seemann P, Mundlos S: Deletion and point mutations of PTHLH cause brachydactyly type E. Am J Hum Genet 2010, 86(3):434-439.

10. Brison N, Tylzanowski P, Debeer P: Limb skeletal malformations-What the HOX is going on? Eur J Med Genet 2011, doi:10.1016/j.ejmg.2011.06.003.

11. Furniss D, Kan SH, Taylor IB, Johnson D, Critchley PS, Giele HP, Wilkie AO: Genetic screening of 202 individuals with congenital limb malformations and requiring reconstructive surgery. J Med Genet 2009, 46(11):730-735.

12. Nakano K, Sakai N, Yamazaki Y, Watanabe H, Yamada N, Sezaki K, Susami T, Tokunaga K, Takato T, Uchinuma E: Novel mutations of the HOXD13 gene in hand and foot malformations. Int Surg 2007, 92(5):287-295.

13. Fantini S, Vaccari G, Brison N, Debeer P, Tylzanowski P, Zappavigna V: A G220V substitution within the $\mathrm{N}$-terminal transcription regulating domain of HOXD13 causes a variant synpolydactyly phenotype. Hum Mol Genet 2009, 18(5):847-860.

14. Waijd $M$, Ishii $Y$, Kurban $M$, Dua-Awereh $M B$, Shimomura $Y$, Christiano AM: Polyalanine repeat expansion mutations in the HOXD13 gene in Pakistani families with synpolydactyly. Clin Genet 2009, 76(3):300-302.

15. Gong L, Wang B, Wang J, Yu H, Ma X, Yang J: Polyalanine repeat expansion mutation of the HOXD13 gene in a Chinese family with unusual clinical manifestations of synpolydactyly. Eur J Med Genet 2011, 54(2):108-111

16. Goodman FR, Giovannucci-Uzielli ML, Hall C, Reardon W, Winter R, Scambler P: Deletions in HOXD13 segregate with an identical, novel foot malformation in two unrelated families. Am J Hum Genet 1998, 63(4):992-1000.

17. Kan S, Johnson D, Giele H, Wilkie AOM: An acceptor splice site mutation in HOXD13 results in variable hand, but consistent foot malformations. Am J Med Genet 2003, 121A:69-74.

18. Lahiri DK, Bye S, Nurnberger Jl, Hodes ME, Crisp M: A non-organic and non-enzymatic extraction method gives higher yields of genomic DNA from whole-blood samples than do nine other methods tested. Biochem Biophys Methods 1992, 25(4):193-205.

19. Goodman FR, Bacchelli C, Brady AF, Brueton LA, Fryns JP, Mortlock DP, Innis JW, Holmes LB, Donnenfeld AE, Feingold M, Beemer FA, Hennekam RC, Scambler PJ: Novel HOXA13 mutations and the phenotypic spectrum of hand-foot-genital syndrome. Am J Hum Genet 2000, 67(1):197-202.

20. Innis JW, Goodman FR, Bacchelli C, Williams TM, Mortlock DP, Sateesh P, Scambler PJ, McKinnon W, Guttmacher AE: A HOXA13 allele with a missense mutation in the homeobox and a dinucleotide deletion in the promoter underlies Guttmacher syndrome. Hum Mutat 2002, 19(5):573-574

21. Kuss $P$, Villavicencio-Lorini P, Witte F, Klose J, Albrecht AN, Seemann P, Hecht J, Mundlos S: Mutant Hoxd13 induces extra digits in a mouse model of synpolydactyly directly and by decreasing retinoic acid synthesis. J Clin Invest 2009, 19(1):146-156.

22. Huang W, Chung UI, Kronenberg HM, de Crombrugghe B: The chondrogenic transcription factor Sox9 is a target of signaling by the parathyroid hormone-related peptide in the growth plate of endochondral bones. Proc Natl Acad Sci 2001, 98(1):160-165.

\section{Pre-publication history}

The pre-publication history for this paper can be accessed here: http://www.biomedcentral.com/1471-2350/13/4/prepub

doi:10.1186/1471-2350-13-4

Cite this article as: Jamsheer et al:: Isolated brachydactyly type E caused by a HOXD13 nonsense mutation: a case report. BMC Medical Genetics 2012 13:4.

\section{Submit your next manuscript to BioMed Central and take full advantage of:}

- Convenient online submission

- Thorough peer review

- No space constraints or color figure charges

- Immediate publication on acceptance

- Inclusion in PubMed, CAS, Scopus and Google Scholar

- Research which is freely available for redistribution 